\title{
Biogeochemistry of asphalt seeps in the North São Paulo Plateau, Brazilian Margin
}

\author{
JING ZHNAG ${ }^{1}$, KAI JIANG ${ }^{2}$, SHOTA KAMBAYASHI ${ }^{3}$, \\ AKIHIRO SAKATOKU ${ }^{4}$, TOSHIRO YAMANAKA ${ }^{5}$, \\ KATSUNORI FUJIKURA ${ }^{6}$, VIVIAN HELENA PELLIZARI ${ }^{7}$
}

${ }^{1}$ Graduate School of Science and Engineering, University of Toyama, 9308555 Japan; jzhang@sci.u-toyama

${ }^{2}$ Graduate School of Science and Engineering, University of Toyama, 9308555 Japan; jiangkai8902@126.com;

${ }^{3}$ Graduate School of Science and Engineering, University of Toyama, 9308555 Japan; kambayashi@kaiseiken.or.jp

${ }^{4}$ Graduate School of Science and Engineering, University of Toyama, 9308555 Japan; sakatoku@sci.u-toyama.ac.jp;

${ }^{5}$ School of Marine Resources and Environment, Tokyo University of Marine Science and Technology, Tokyo, 1088477, Japan; t.yamanaka@kaiyodai.ac.jp

${ }^{6}$ Department of Marine Biodiversity Research, Japan Agency for Marine-Earth Science and Technology; fujikura@jamstec.go.jp

${ }^{7}$ Instituto Oceanográfico, Departamento de Oceanografia Biológica, Universidade de São Paulo, São Paulo, 05508120,Brazil; vivianp@usp.br

A roughly $5.6 \mathrm{~km}$ asphalt seep band was found at a depth of $2700 \mathrm{~m}$ in the Brazilian margin, by nine deep sea dives using the manned research submersible SHINKAI 6500. This type of seep represents the third discovery worldwide, following those in the Gulf of Mexico and off Angola. There was no evidence of chemosynthesis based megabenthic fauna or any sediment bacterial mats, gas seepage, and carbonate rock in/around the seeps. Sea water, porewater, sediment and bilogical samples were colleced and taken back to the laboratory on land.

The silica concentration, as a chemical geothermometer, showed a steep gradient in the pore water, which indicates the possibility of an active brine system operating in the seepage area. In the middle and southwest asphalt seep band, relatively low rare earth element conce ntrations and weakly positive Ce anomalies of sediment revealed the asphalt seep was newer than that in the northeast. Stable carbon and nitrogen isotopes are good tracers for understanding the food sources of heterotrophs and trophic pathways within food webs. Our results suggest both oil and organic matters in sediment maybe provide a carbon source for the benthic animals. This study may provide useful information to clarify the impact of heavy hydrocarbon seepage on the marine ecosystem. 